\title{
Patient perception matters in weight management
}

\author{
Ivana T. Croghan ${ }^{1,2,5}$, Jill M. Huber ${ }^{2}$, Ryan T. Hurt ${ }^{3}$, Darrell R. Schroeder ${ }^{4}$, Mark L. Wieland ${ }^{2}$, Lila J. Rutten ${ }^{5}$ \\ and Jon O. Ebbert ${ }^{1,2,5}$ \\ ${ }^{1}$ Department of Medicine Clinical Research Office, Department of Internal Medicine, Mayo Clinic, Rochester, MN, USA \\ ${ }^{2}$ Division of Primary Care Internal Medicine, Mayo Clinic, Rochester, MN, USA \\ ${ }^{3}$ Division of General Internal Medicine, Department of Internal Medicine, Mayo Clinic, Rochester, MN, USA \\ ${ }^{4}$ Division of Biomedical Statistics and Informatics, Department of Health Sciences Research, Mayo Clinic, Rochester, MN, USA \\ ${ }^{5}$ Robert D. and Patricia E. Kern Center for the Science of Health Care Delivery, Mayo Clinic, Rochester, MN, USA
}

\begin{abstract}
In a survey of 471 patients, we collected self-reported weight and height data and asked about self-perceptions of provider support toward weight loss and other weight management concerns. Multivariable analysis found that respondents with higher body mass index (BMI) were more likely to report that a physician had told them that they were overweight ( $\mathrm{OR}=3.49,95 \% \mathrm{Cl} 2.06-5.89, P<0.001)$. However, this conversation was less likely to change their personal view of their weight $\left(O R=0.62\right.$ per $5 \mathrm{~kg} / \mathrm{m}^{2}$, $95 \% \mathrm{Cl} 0.45-0.86, P=0.004)$, or motivate them to lose weight ( $\mathrm{OR}=0.67 \mathrm{per} 5 \mathrm{~kg} / \mathrm{m}^{2}, 95 \%$ $\mathrm{Cl} 0.50-0.91, P=0.009)$. Higher $\mathrm{BMI}$ was associated with higher weight-loss goals $(P<0.001)$, while anticipated time to achieve those goals was increased $(P<0.001)$. Physician involvement in weight management was important, but the patients' needs and experiences differed by BMI. Approaches to addressing barriers and identifying resources for weight management should be tailored to individuals by considering BMI.
\end{abstract}

Key words: health care delivery; primary care; survey research

Received 14 June 2017; revised 17 July 2017; accepted 11 August 2017; first published online 21 November 2017

\section{Introduction}

In the United States, $37 \%$ of adults and $17 \%$ of youth are considered obese (Ogden et al., 2015). Rates of obesity differ by age, gender, and race (Ogden et al., 2015). Obesity is a major public health and clinical concern because of its association with increased morbidity, mortality, and health care expenditures (Jensen et al., 2014). The current guidelines for the management of overweight or obese adults call for primary care providers (PCPs) to identify, counsel, and offer treatment management for patients with obesity (ie, ask, advise, treat) (Jensen et al., 2013).

Counseling by the PCP can increase patient motivation to engage in weight loss (Huang et al., 2004;

Correspondence to: Ivana T Croghan, $\mathrm{PhD}$, Department of Internal Medicine, Mayo Clinic, 200 First Street SW, Rochester, MN 55905, USA. Email: croghan.ivana@mayo.edu
Bennett et al., 2014; 2015). Currently only one of three patients who are overweight or obese is identified as such, and among those identified, only half are advised to lose weight and only one of five receive counseling (Bennett et al., 2014). Although patients with obesity expect their PCPs to discuss and counsel them on weight loss, many physicians will not or cannot broach the subject (Huang et al., 2004). For PCPs, potential barriers to counseling include lack of time, limited funding for resources, infrastructure, and training, and concerns about damaging the patient-doctor relationship (Huang et al., 2004; Pollak et al., 2012; Gudzune et al., 2014; Bleich et al., 2015; McGowan, 2016). Focus groups have concluded that if PCPs cannot provide ongoing weight management support to their patients, they can at least identify obesity, refer their obese/overweight patients to a weight management expert, provide patient accountability, and cheerlead (Bennett et al., 2014).

(C) Cambridge University Press 2017. This is an Open Access article, distributed under the terms of the Creative Commons Attribution licence (http://creativecommons.org/licenses/by/4.0/), which permits unrestricted re-use, distribution, and reproduction in any medium, provided the original work is properly cited. 
Studies of PCPs perceptions of their role in assisting their patients with weight loss are limited, and even less is known about the experiences and expectations of patients in primary care. To address this gap, we conducted a needs-assessment survey of patient experiences and expectations regarding weight management in the primary care setting to inform weight management in clinical care.

\section{Methods}

The study was approved by the Mayo Clinic Institutional Review Board; the use of implied consent (ie, consent was implied if the survey was completed and returned) was allowed. We conducted a cross-sectional survey involving a convenience sample of patients' presenting to an office visit at a primary care clinic at Mayo Clinic (Rochester, MN, USA). From February 2013 through July 2013, all patients seen for a primary care visit received an anonymous survey, a cover letter explaining the purpose of the study, and a stamped return envelope. Patients either returned the survey to the receptionist or mailed it after the visit.

The survey included a subset of validated questions from the National Health and Nutrition Examination Survey (Yaemsiri et al., 2011) and questions (developed by the study team) related to weight management in primary care. Specifically, the questionnaire included the following constructs adapted from NHANES: self-reported height and weight [to calculate body mass index (BMI)] (Center for Disease Control, 2015), weight selfperception, current and past weight-loss efforts, resources used for weight loss, and experience of discussions about weight with the PCP. We also assessed expectations regarding the need for weight loss management in the primary care setting. We conducted a pilot test before full implementation of the survey $(n=25)$.

Redcap database was used (Harris et al., 2009). Data are summarized using mean \pm SD for continuous variables and frequency counts and percentages for categorical variables. Respondent characteristics are summarized overall and stratified by BMI categories. Comparisons across BMI categories were performed by using analysis of variance (ANOVA) for continuous variables and the $\chi^{2}$ test for categorical variables. The frequency of various medical conditions was compared across BMI categories using the Cochran-Armitage trend test. All other analyses were restricted to respondents whose BMI was $\geqslant 25.0 \mathrm{~kg} / \mathrm{m}^{2}$ and who perceived themselves as overweight. For this subset of patients, previous weight-related health care experiences, current expectations, perceived barriers to weight loss, and needs from PCP were summarized and compared across BMI categories by using ANOVA for continuous variables and the Cochran-Armitage trend test for dichotomous variables. Multiple logistic regression analyses were performed to assess whether health care experiences were independently associated with BMI, adjusting for age and sex. Findings from the multivariable analyses are summarized as odds ratio and corresponding $95 \%$ confidence interval for a $5 \mathrm{~kg} / \mathrm{m}^{2}$ increase in BMI. In all cases, two-sided tests were used; $P$ values $\leqslant 0.05$ denote statistical significance.

\section{Results}

Of the 500 surveys collected, 29 did not include enough demographic information to be evaluated for this study. We report on 471 returned evaluable surveys. For BMI, the mean \pm SD for all survey respondents was $27.9 \pm 6.0 \mathrm{~kg} / \mathrm{m}^{2}$ (Table 1). Of the 471 respondents, $167(35.5 \%)$ were underweight or healthy weight $\left(\mathrm{BMI}<25 \mathrm{~kg} / \mathrm{m}^{2}\right), 164$ $(34.8 \%)$ were overweight (BMI $25-29.9 \mathrm{~kg} / \mathrm{m}^{2}$ ), and $140(29.7 \%)$ were obese $\left(\mathrm{BMI} \geqslant 30 \mathrm{~kg} / \mathrm{m}^{2}\right)$.

Self-perception of weight differed significantly $(P<0.001)$ across BMI categories (Table 2). Among respondents in the normal BMI range, $15 \%$ perceived themselves as overweight and $6.6 \%$ as underweight. Among those in the overweight BMI category, $1.2 \%$ thought they were underweight and $25.0 \%$ thought they were in the normal range. In the obese BMI category, $7 \%$ thought they were the in the normal range. As BMI increased, reported comorbidities increased significantly. A significantly greater proportion of obese respondents reported having type 2 diabetes mellitus, high cholesterol, high blood pressure, arthritis of the knee/hip, and obstructive sleep apnea.

The expectation to have weight discussed at the PCP visit did not differ by calculated BMI 
Table 1 Respondent characteristics, stratified by body mass index category

\begin{tabular}{|c|c|c|c|c|c|c|c|}
\hline \multirow[b]{2}{*}{ Characteristic } & \multirow[b]{2}{*}{$\begin{array}{l}\text { Overall } \\
(n=471)\end{array}$} & \multicolumn{5}{|c|}{ Body mass index $\left(\mathrm{kg} / \mathrm{m}^{2}\right)$} & \multirow[b]{2}{*}{$\begin{array}{l}P \\
\text { value }^{a}\end{array}$} \\
\hline & & $\begin{array}{l}\leqslant 24.9 \\
(n=167)\end{array}$ & $\begin{array}{l}25.0-29.9 \\
(n=164)\end{array}$ & $\begin{array}{l}30.0-34.9 \\
(n=86)\end{array}$ & $\begin{array}{l}35.0-39.9 \\
(n=35)\end{array}$ & $\begin{array}{l}\geqslant 40.0 \\
(n=19)\end{array}$ & \\
\hline Age, mean \pm SD (years) & $52.7 \pm 17.4$ & $49.6 \pm 18.3$ & $54.4 \pm 17.3$ & $57.0 \pm 16.0$ & $51.0 \pm 14.9$ & $49.0 \pm 17.1$ & 0.01 \\
\hline Female sex $[n .(\%)]$ & $298(63.3)$ & $125(74.9)$ & $86(52.4)$ & $47(54.7)$ & $26(74.3)$ & $14(73.7)$ & $<0.001$ \\
\hline Race/ethnicity [ $n(\%)]$ & & & & & & & 0.31 \\
\hline White, non-Hispanic & 432 (91.7) & $154(92.2)$ & 152 (92.7) & $78(90.7)$ & $33(94.3)$ & $15(79.0)$ & \\
\hline White, Hispanic & $14(3.0)$ & $2(1.2)$ & $6(3.7)$ & $4(4.7)$ & $0(0.0)$ & $2(10.5)$ & \\
\hline Black/African American & $6(1.3)$ & $1(0.6)$ & $1(0.6)$ & $2(2.3)$ & $2(5.7)$ & $0(0.0)$ & \\
\hline $\begin{array}{l}\text { Native American/ } \\
\text { Alaska Native }\end{array}$ & $3(0.6)$ & $1(0.6)$ & $0(0.0)$ & $0(0.0)$ & $0(0.0)$ & $2(10.5)$ & \\
\hline Asian & $11(2.3)$ & $7(4.2)$ & $3(1.8)$ & $1(1.2)$ & $0(0.0)$ & $0(0.0)$ & \\
\hline Multiple races & $5(1.1)$ & $2(1.2)$ & $2(1.2)$ & $1(1.2)$ & $0(0.0)$ & $0(0.0)$ & \\
\hline Marital status $[n(\%)]$ & & & & & & & 0.66 \\
\hline $\begin{array}{l}\text { Married/living as } \\
\text { married }\end{array}$ & $321(68.2)$ & $123(73.7)$ & $114(69.5)$ & $61(70.9)$ & $20(57.1)$ & $13(68.4)$ & \\
\hline Engaged to be married & $2(0.4)$ & $1(0.6)$ & $0(0.0)$ & $0(0.0)$ & $1(2.9)$ & $0(0.0)$ & \\
\hline Separated/divorced & $48(10.2)$ & $18(10.8)$ & $13(7.9)$ & $10(11.6)$ & $7(20.0)$ & $0(0.0)$ & \\
\hline Widowed & $36(7.6)$ & $10(6.0)$ & $16(9.8)$ & $9(10.5)$ & $0(0.0)$ & $1(5.3)$ & \\
\hline Never married & $64(13.6)$ & $25(15.0)$ & $21(12.8)$ & $6(7.0)$ & $7(20.0)$ & $5(26.3)$ & \\
\hline Education $[n(\%)]$ & & & & & & & 0.07 \\
\hline Some high school & $15(3.2)$ & $4(2.4)$ & $5(3.0)$ & $4(4.7)$ & $2(5.7)$ & $0(0.0)$ & \\
\hline High school graduate & $71(15.1)$ & $14(8.4)$ & $28(17.1)$ & $20(23.3)$ & $3(8.6)$ & $6(31.6)$ & \\
\hline Some college & $142(30.1)$ & $53(31.7)$ & $42(25.6)$ & $25(29.1)$ & $16(45.7)$ & $6(31.6)$ & \\
\hline 4-year college graduate & $140(29.7)$ & $59(35.3)$ & $50(30.5)$ & $18(20.9)$ & $7(20.0)$ & $6(31.6)$ & \\
\hline Graduate degree & $103(21.9)$ & $37(22.2)$ & $39(23.8)$ & $19(22.1)$ & $7(20.0)$ & $1(5.3)$ & \\
\hline Employment $[n(\%)]$ & & & & & & & 0.32 \\
\hline $\begin{array}{l}\text { Employed/self- } \\
\text { employed }\end{array}$ & $286(60.7)$ & $94(56.3)$ & $104(63.4)$ & $51(59.3)$ & $26(74.3)$ & $11(57.9)$ & \\
\hline Retired & $128(27.2)$ & $48(28.7)$ & $45(27.4)$ & $26(30.2)$ & $5(14.3)$ & $4(21.1)$ & \\
\hline $\begin{array}{l}\text { Taking care of house/ } \\
\text { family }\end{array}$ & $19(4.0)$ & $11(6.6)$ & $5(3.0)$ & $3(3.5)$ & $0(0.0)$ & $0(0.0)$ & \\
\hline Student & $14(3.0)$ & $8(4.8)$ & $5(3.0)$ & $1(1.2)$ & $0(0.0)$ & $0(0.0)$ & \\
\hline Disabled & $14(3.0)$ & $4(2.4)$ & $2(1.2)$ & $4(4.7)$ & $2(5.7)$ & $2(10.5)$ & \\
\hline Unemployed & $10(2.1)$ & $2(1.2)$ & $3(1.8)$ & $1(1.2)$ & $2(5.7)$ & $2(10.5)$ & \\
\hline
\end{tabular}

\footnotetext{
${ }^{a}$ Age was compared across body mass index groups by using analysis of variance; categorical variables were compared by using the $\chi^{2}$ test. When comparing categorical variables across groups, the variables were dichotomized as follows: sex (male versus female); race (white non-Hispanic versus all other races); marital status (married/living as married versus all other categories); education (4-year college graduate or graduate degree versus all other categories); and employment (employed/self-employed versus all other categories).
}

(Table 3). Patients in the overweight category and those in the highest BMI category had the greatest interest in having their PCP discuss weight during the visit (61\% and $63 \%$, respectively). Respondents with higher BMIs more frequently reported being told that they were overweight, but these conversations were less likely to change their personal views of their weight status or motivate them to lose weight. From multivariable analysis, respondents with higher BMI were less likely to report that a physician telling them they were overweight changed their personal view of their weight status $\left(\mathrm{OR}=0.62\right.$ per $5 \mathrm{~kg} / \mathrm{m}^{2}, 95 \%$ CI $0.45-0.86, P=0.004)$, or motivated them to lose weight $\left(\mathrm{OR}=0.67\right.$ per $5 \mathrm{~kg} / \mathrm{m}^{2}, 95 \%$ CI $0.50-0.91$, $P=0.009)$.

A higher percentage of patients with higher BMIs were trying to lose weight at the time of the survey (with goals of losing $36 \%$ versus $12 \%$ of their total body weight for obese and overweight respondents, respectively; $P<0.001)$. As BMI increased, the mean personal goal for weight loss and anticipated time frame to achieve it increased and the importance of financial limitations, 
Table 2 Medical conditions and self-perception of weight, stratified by body mass index category

\begin{tabular}{|c|c|c|c|c|c|c|c|}
\hline \multirow[b]{2}{*}{$\begin{array}{l}\text { Medical condition or } \\
\text { perception }\end{array}$} & \multirow[b]{2}{*}{$\begin{array}{l}\text { Overall } \\
(n=471)\end{array}$} & \multicolumn{5}{|c|}{ Body mass index $\left(\mathrm{kg} / \mathrm{m}^{2}\right)$} & \multirow[b]{2}{*}{$\begin{array}{l}P \\
\text { value }^{\mathrm{a}}\end{array}$} \\
\hline & & $\begin{array}{l}\leqslant 24.9 \\
(n=167)\end{array}$ & $\begin{array}{l}25.0-29.9 \\
(n=164)\end{array}$ & $\begin{array}{l}30.0-34.9 \\
(n=86)\end{array}$ & $\begin{array}{l}35.0-39.9 \\
(n=35)\end{array}$ & $\begin{array}{l}\geqslant 40.0 \\
(n=19)\end{array}$ & \\
\hline Coronary artery disease & $36(7.6)$ & $7(4.2)$ & $14(8.5)$ & $10(11.6)$ & $3(8.6)$ & $2(10.5)$ & 0.07 \\
\hline Current depression ${ }^{\mathrm{b}}$ & $48(11.4)$ & $14(10.0)$ & $13(8.4)$ & $13(17.1)$ & $5(15.2)$ & $3(16.7)$ & 0.10 \\
\hline Diabetes mellitus, type 2 & $48(10.2)$ & $7(4.2)$ & $18(11.0)$ & $12(14.0)$ & $4(11.4)$ & $7(36.8)$ & $<0.001$ \\
\hline Fibromyalgia & $22(4.7)$ & $5(3.0)$ & $6(3.7)$ & $7(8.1)$ & $3(8.6)$ & $1(5.3)$ & 0.08 \\
\hline History of depression & $139(29.5)$ & $49(29.3)$ & $41(25.0)$ & $24(27.9)$ & $18(51.4)$ & $7(36.8)$ & 0.09 \\
\hline High cholesterol & $140(29.7)$ & $40(24.0)$ & $49(29.9)$ & $30(34.9)$ & $15(42.9)$ & $6(31.6)$ & 0.02 \\
\hline High blood pressure & $129(27.4)$ & $39(23.4)$ & $41(25.0)$ & $31(36.0)$ & $12(34.3)$ & $6(31.6)$ & 0.04 \\
\hline Knee or hip arthritis & 75 (15.9) & $13(7.8)$ & $23(14.0)$ & $20(23.3)$ & $13(37.1)$ & $6(31.6)$ & $<0.001$ \\
\hline Obstructive sleep apnea & $60(12.7)$ & $11(6.6)$ & $16(9.8)$ & $18(20.9)$ & $9(25.7)$ & $6(31.6)$ & $<0.001$ \\
\hline $\begin{array}{l}\text { Self-perception of } \\
\text { weight }\end{array}$ & & & & & & & $<0.001$ \\
\hline Underweight & $13(2.8)$ & $11(6.6)$ & $2(1.2)$ & $0(0.0)$ & $0(0.0)$ & $0(0.0)$ & \\
\hline About the right weight & $178(37.8)$ & $131(78.4)$ & $41(25.0)$ & $6(7.0)$ & $0(0.0)$ & $0(0.0)$ & \\
\hline Overweight & $280(59.4)$ & $25(15.0)$ & $121(73.8)$ & $80(93.0)$ & $35(100.0)$ & $19(100.0)$ & \\
\hline
\end{tabular}

${ }^{a}$ Cochran-Armitage trend test.

${ }^{\mathrm{b}}$ Current depression was defined as Patient Health Questionnaire- 2 score $\geqslant 3$. Percentages are based on 421 with available data ( $n=140, n=154, n=76, n=33$, and $n=18$ for the body mass index subcategories, respectively).

physical limitations, lack of overall general support, and fatigue increased.

A greater proportion of respondents with higher BMIs expressed the expectation that their PCP would discuss health consequences of overweight and obesity, review weight loss medications options, provide support and follow-up, offer a weight loss program in primary care, and provide access to specialists, weight-loss programs, and weight-management surgery.

\section{Discussion}

Most respondents had accurate weight selfperceptions. As calculated BMI increased, respondents reported having more comorbidities and being told that they were overweight by their PCP, but those with higher BMI were less likely to indicate that these conversations changed their personal view of their weight status or motivated them to lose weight. One explanation for this is these patients may have been previously told they are obese and may have tried and failed numerous types of interventions to lose weight. Overweight patients on average wanted to lose $11 \%$ of their current weight, and patients with obesity wanted to lose $35 \%$ compared with the recommended goal of 2-5\% loss from baseline weight (Donato et al., 1998;
Weight-control Information Network (WIN) et al., 2005). This highlights the importance of PCPs discussing reasonable goals as increased frequency of PCP contact has been associated with more realistic weight loss goals(Dutton et al., 2010). As BMI increased, the most common perceived barriers were financial, physical, and support limitations and increased fatigue. As weight increases, the ability to exercise can decrease leading to a deconditioning and fatigue (Mehta and Cavuoto, 2017). In addition, many obesity treatments (eg, higher quality of food, exercise programs, athletic centers, obesity medications, and bariatric surgery) can be financially prohibitive and may not be covered by health insurance.

We observed that most patients who were overweight or obese wanted to discuss their weight at the current visit with the PCP. Discussions about weight require consideration of message content and delivery. In a recent study of 600 patients who were overweight or obese in a primary care setting, PCPs who were perceived to 'judge' patients had less success in engaging the patient in weight loss than those patients with PCPs who discussed but did not 'judge' (13.5\% versus $20.1 \%$, respectively) (Gudzune et al., 2014). Some of the skills and attitudes needed when providing weight management counseling include awareness of the weight management literature, use of nonjudgmental 
Table 3 Past experience and current expectations for weight-related discussion: stratified by body mass index category ${ }^{a}$

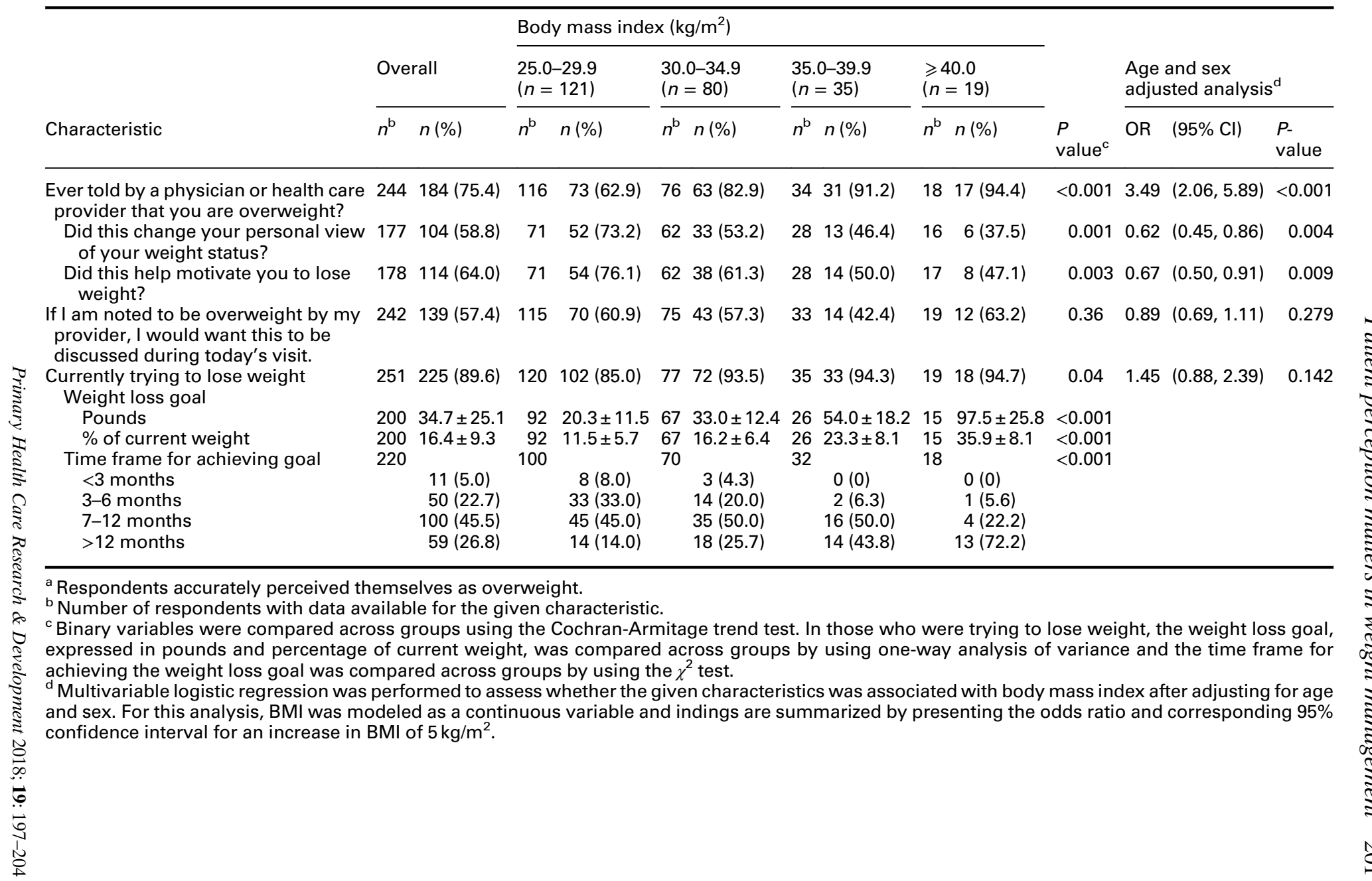


language, and focusing on the patient and not the obesity diagnosis when discussing possible management plans. In addition, we recommend following the five As - ask permission to discuss weight concerns, assess their BMI, advise on health risks, agree on realistic weight loss expectations and goals, and assist in identifying, and addressing barriers (McGowan, 2016).

Many patients who are overweight or obese want support from their PCPs for weight loss; but weight concerns are inconsistently addressed and support is infrequently provided. Whether this is linked to lack of adequate tools for identifying or diagnosing obesity or lack of BMI documentation is unknown. In some clinical situations, patients with obesity and other co-morbid conditions had BMI documented compared with otherwise healthy patients who were obese but otherwise healthy and did not have their BMI documented (Melamed et al., 2009). In another study, obesity was underdiagnosed $(14.4 \%$ of patients with $\mathrm{BMI} \geqslant 30 \mathrm{~kg} / \mathrm{m}^{2}$ ), and only $5 \%$ of the patients who were overweight or obese recalled being counseled by their PCP on weight and exercise (Huang et al., 2004). Patients who recalled the counseling interaction understood the risks of obesity and benefits of weight loss, and they were more confident and ready to lose weight (Huang et al., 2004). Some barriers to initiating weight management discussions which have been identified by PCPs included pessimism about their patients' desire and ability to lose weight, pessimism about the effectiveness weight loss program itself, lack of comprehensive obesity management resources, lack of time, high patient volume, underuse of clinical resources with expertise (eg, dieticians), and lack of counseling skills and knowledge concerning clinical best practice for weight management (Huang et al., 2004).

In a recent focus group study of 26 PCPs, recommendations for effective weight management care in primary care included (1) provision of feedback to PCPs by weight management coaches in an efficient and actionable manner; (2) integration of weight concerns into practice, with an intake questionnaire about weight management that could be quickly reviewed and discussed; (3) a referral system to have patients receive weight counseling from expert coaches and to facilitate telephone support; and (4) improving the financial feasibility of incorporating weight management into the clinical encounter (Bennett et al., 2014). A multidisciplinary model of care (ie, incorporating providers with specialized skills and expertise from different health care professions) has been successfully used in many clinical practices as a way to reduce time and financial burden (Batsis et al., 2015; Luo et al., 2016).

The US guidelines recommend that PCPs assist patients with weight management (Jensen et al., 2014). The treatment algorithm for weight management which could be adapted to individual practices can be based on resource availability (Donato et al., 1998). It is recommended that physicians receive training in motivational interviewing (MI) messaging early in their career (Huang et al., 2004; Burton et al., 2016; McGowan, 2016). Use of MI may help clinicians facilitate behavior change in patients who are overweight or obese, since it has been shown that patients of PCPs who use MI strategies have lost more weight (Pollak et al., 2012), this in turn will increase the clinician's confidence in their ability to help patients. Physician confidence in their ability to help their patients in weight management is crucial for the effectiveness of the behavioral intervention; conversely, lack of appropriate skills can compromise the effectiveness of clinical weight loss interventions and damage the clinicianpatient relationship (Pollak et al., 2012).

Addressing weight management issues in the clinical setting is challenging and complex. Clinicians may benefit from training in evidence-based approaches to weight management counseling. Furthermore, greater connectivity of the clinical setting to community resources to support weight management are needed, particularly to address potential disparities encountered by patients in socioeconomic conditions associated with overweight and obesity Weight management efforts must be tailored to individuals' needs and resources (Overweight And Obesity in the Wester Pacific Region, 2017).

Our study has several limitations. The survey was administered at a single clinic and respondents were predominantly non-Hispanic whites limiting the generalizability of our findings. The survey was administered to a convenience sample, which may also limit generalizability. Weight and height were self-reported and not confirmed with clinical measurements, so the calculated BMIs may be inaccurate. Finally, we did not assess the message 
content or quality of message delivery when the PCP discussed weight management and experience with the PCP past messaging may have influenced responses.

Involving PCP in weight management is important for patients who are overweight or obese. We observed that patient needs, perceptions, and experiences relating to body weight and weight loss in the primary care setting differ by BMI. Our results highlight the need for improved resources and training to support PCPs in an effort to offer advice and support to patients with body weight concerns. Our data suggest that approaches to addressing barriers and provision of resources for weight management in the primary care setting could be tailored to BMI category.

\section{Acknowledgment}

The study was supported in part by the Mayo Clinic Department of Medicine. The authors especially thank the exceptional research staff of the Mayo Clinic Department of Medicine Clinical Research Office for their patience and persistence in helping to collect, compile, and organize these data. They also thank the staff of the Department of Medicine Primary Care Internal Medicine and the patients without whom this project would not have been possible.

\section{Financial Support}

The study was supported in part by the Mayo Clinic Department of Medicine. The data entry system used was RedCap, supported in part by the Center for Clinical and Translational Science award (UL1 TR000135) from the National Center for Advancing Translational Sciences (NCATS).

\section{Conflicts of Interest}

All authors declare no support from any organization for the submitted work; no financial relationships with any organizations that might have an interest in the submitted work in the previous 3 years; and no other relationships or activities that could appear to have influenced the submitted work.

\section{Ethical Standards}

The authors assert that all procedures contributing to this work comply with the ethical standards of the Mayo Clinic Institutional Review Board guidelines on human experimentation in accordance with the Declaration of Helsinki of 1975 , as revised in 2008. Protocol-approved passive consent was obtained from all study participants before study initiation.

\section{References}

Batsis, J.A., Huyck, K.L. and Bartels, S.J. 2015: Challenges with the medicare obesity benefit: practical concerns \& proposed solutions. Journal of General Internal Medicine 30, 118-22.

Bennett, W.L., Gudzune, K.A., Appel, L.J. and Clark, J.M. 2014: Insights from the POWER practice-based weight loss trial: a focus group study on the PCP's role in weight management. Journal of General Internal Medicine 29, 50-58.

Bennett, W.L., Wang, N.Y., Gudzune, K.A., Dalcin, A.T., Bleich, S.N., Appel, L.J. and Clark, J.M. 2015: Satisfaction with primary care provider involvement is associated with greater weight loss: results from the practice-based POWER trial. Patient Education and Counseling 98, 1099-105.

Bleich, S.N., Bandara, S., Bennett, W.L., Cooper, L.A. and Gudzune, K.A. 2015: U.S. health professionals' views on obesity care, training, and self-efficacy. American Journal of Preventive Medicine 48, 411-18.

Burton, A.M., Brezausek, C.M., Agne, A.A., Hankins, S.L., Willett, L.L. and Cherrington, A.L. 2016: Evaluation of a workshop to improve residents' patient-centred obesity counselling skills. Postgraduate Medical Journal 92, 455-59.

Center for Disease Control 2015: Body mass index (BMI) [online]. Retrieved June 2015 from https://www.cdc.gov/ healthyweight/assessing/bmi/index.html.

Donato, K.A., Pi-Sunyer, F.X., Becker, D.M., Bouchard, C., Carleton, R.A., Colditz, G.A., Dietz, W.H., Foreyt, J.P., Garrison, R.J., Grundy, S.M., Hansen, B.C., Higgins, M., Hill, J.O., Howard, B.V., Kuczmarski, R.J., Kumanyika, S., Legako, R.D., Prewitt, T.E., Rocchini, A.P., Snetselaar, L.G., Weintraub, M., Williamson, D.F., Wilson, G.T., Brown, C.D., Ernst, N., Hill, D.R., Horan, M.J., Kiley, J.P., Obarzanck, E., Hubbard, V.S., Schriger, D. and Chiquette, E., Expert Panel Identification. 1998: Executive summary of the clinical guidelines on the identification, evaluation, and treatment of overweight and obesity in adults. Archives of Internal Medicine 158, 1855-867.

Dutton, G.R., Perri, M.G., Dancer-Brown, M., Goble, M. and Van Vessem, N. 2010: Weight loss goals of patients in a health maintenance organization. Eating Behaviors 11, 74-78.

Gudzune, K.A., Bennett, W.L., Cooper, L.A. and Bleich, S.N. 2014: Perceived judgment about weight can negatively influence weight loss: a cross-sectional study of overweight and obese patients. Preventive Medicine 62, 103-7. 
Harris, P.A., Taylor, R., Thielke, R., Payne, J., Gonzalez, N. and Conde, J.G. 2009: Research electronic data capture (REDCap) - a metadata-driven methodology and workflow process for providing translational research informatics support. Journal of Biomedical Informatics 42, 377-81.

Huang, J., Yu, H., Marin, E., Brock, S., Carden, D. and Davis, T. 2004: Physicians' weight loss counseling in two public hospital primary care clinics. Journal of the Association of American Medical Colleges 79, 156-61.

Jensen, M.D., Ryan, D.H., Apovian, C.M., Ard, J.D., Comuzzie, A.G., Donato, K.A., Hu, F.B., Hubbard, V.S., Jakicic, J.M., Kushner, R.F., Loria, C.M., Millen, B.E., Nonas, C.A., Pi-Sunyer, F.X., Stevens, J., Stevens, V.J., Wadden, T.A., Wolfe, B.M. and Yanovski, S.Z., American College of Cardiology/American Heart Association Task Force on Practice Guidelines and Obesity Society. 2014: 2013 AHA/ACC/TOS guideline for the management of overweight and obesity in adults: a report of the American College of Cardiology/American Heart Association Task Force on Practice Guidelines and The Obesity Society. Journal of the American College of Cardiology 63 (25 Pt B), 2985-3023.

Jensen, M.D., Ryan, D.H., Apovian, C.M., Ard, J.D., Comuzzie, A.G., Donato, K.A., et al. 2013: AHA/ACC/ TOS guideline for the management of overweight and obesity in adults: a report of the American College of Cardiology/American Heart Association Task Force on Practice Guidelines and The Obesity Society. Journal of the American College of Cardiology 63 (25 Pt B), 2985-3023.

Luo, Z., Chen, Q., Annis, A.M., Piatt, G., Green, L.A., Tao, M. and Holtrop, J.S. 2016: A comparison of health plan- and provider-delivered chronic care management models on patient clinical outcomes. Journal of General Internal Medicine 31, 762-70.
McGowan, B.M. 2016: A practical guide to engaging individuals with obesity. Obesity Facts 9, 182-92.

Mehta, R.K. and Cavuoto, L.A. 2017: Relationship between BMI and fatigability is task dependent. Human Factors 59, 722-33.

Melamed, O.C., Nakar, S. and Vinker, S. 2009: Suboptimal identification of obesity by family physicians. American Journal of Managed Care 15, 619-24.

Ogden, CL, Carroll, MD, Fryar, CD and Flegal, KM 2015: Prevalence of obesity among adults and youth: United States, 2011-2014 [online], NCHS data brief no. 219. https:// www.cdc.gov/nchs/data/databriefs/db219.pdf.

Overweight and Obesity in the Wester Pacific Region 2017: Manila, Philippines. World Health Organization. Regional Office for the Western Pacific., Licence: CC BY-NC-SA 3.0 IGO.

Pollak, K.I., Coffman, C.J., Alexander, S.C., Tulsky, J.A., Lyna, P., Dolor, R.J., Cox, M.E., Brouwer, R.J., Bodner, M.E. and Ostbye, T. 2012: Can physicians accurately predict which patients will lose weight, improve nutrition and increase physical activity? Family Practice 29, 553-60.

Weight-control Information Network (WIN), National Institutes of Health, National Institute of Dieabetes and Digestive and Kidney Diseases and US Department of Health and Human Services 2005: Talking with patients about weight loss: tips for primary care providers [online]. Retrieved from https://www.niddk.nih.gov/healthinformation/health-topics/weight-control/talking-with-patientsabout-weight-loss-tips-for-primary-care/Documents/Talking WPAWL.pdf.

Yaemsiri, S., Slining, M.M. and Agarwal, S.K. 2011: Perceived weight status, overweight diagnosis, and weight control among US adults: the NHANES 2003-2008 study. International Journal of Obesity 35, 1063-70. 